\title{
A experiência comunitária e a vivência da metrópole: o prelúdio, de William Wordsworth, à luz de Walter Benjamin
}

\author{
Communal erfahrung and metropolitan erlebenis: the prelude, by William Wordsworth, through the lens of \\ Walter Benjamin
}

\section{Angiuli Copetti de Aguiar (10}

Universidade Federal de Santa Maria - UFSM - Santa Maria - Rio Grande do Sul - Brasil

\begin{abstract}
Resumo: Em seu poema autobiográfio, O Prelúdio, o poeta inglês William Wordsworth empenha-se em encontrar em sua memória os eventos que deram forma à sua vida subjetiva e reavaliar suas experiências passadas à luz de sua consciência presente. Com este trabalho, tivemos por objetivo analisar os tipos de experiências descritas por Wordsworth e a relação que mantém com o ambiente que as geraram. Para tanto, recorremos aos conceitos do filósofo Walter Benjamin de 'experiência', 'vivência' e 'choque' e analisamos excertos de $O$ Prelúdio a partir dessas categorias. Constatamos que as experiências se encontram especialmente na infância de Wordsworth no campo, em meio à sua pequena comunidade rural. Vivências têm lugar no relato como fundo contra $\circ$ qual as experiências vivas mostram-se mais nítida, especialmente como contraste entre a vida urbana e a campestre. Choques, por outro lado, aparecem como momentos marcados na memória por sua singularidade e inefabilidade, que assombram o biógrafo ainda anos mais tarde, sem jamais desvelarem por completo seu significado. Concluímos que, em O Prelúdio, o campo e a comunidade é o locus da experiência viva, enquanto que a cidade oferece apenas vivências ao sujeito, embora, para o poeta, momentos de choque possam resgatar das vivências lampejos de experiência autêntica.
\end{abstract}

Palavra-chave: Experiência. Vivência. William Wordsworth. Walter Benjamin. Poesia.

Abstract: In his autobiographical poem The Prelude, the English poet William Wordsworth strives to find in his memory the events that gave shape to his subjective life and to reassess his experiences through the lens of his present consciousness. In this essay, we intended to analyze the types of experience described by Wordsworth and the relationship they hold with the environment which gave them birth. With this purpose we employed Walter Benjamin's concepts of 'erfahrung', 'erlebnis' and 'shock', and analyzed excerpts from The Prelude through these categories. We observed that experiences of erfahrung are found especially in Wordsworth's childhood in the countryside, amidst his little rural community. Experiences of erlebnis take place in the narrative as backgrounds against which erfahrung experiences are shown more clearly, especially in the contrast between urban and rural life. Shocks, on the other hand, appear as moments impressed on the memory by their singularity and ineffability, and which haunt the poet still years later without ever fully disclosing their meaning. We concluded that in The Prelude, the countryside and the community are the locus of living erfahrung experiences while the city offers only erlebnis to the subject, although, for the poet, moments of shock can rescue from the erlebnis flashes of authentic experience.

Keywords: Erfahrung. Erlebnis. William Wordsworth. Walter Benjamin. Poetry 


\section{Introdução}

The prelude or, the growth of a poet's mind; an autobiographical poem ${ }^{1}$ (1850), do poeta inglês William Wordsworth (1770-1850) (ou apenas The Prelude, como é comumente referido) é um extenso poema em verso branco que narra a vida de seu autor e que mescla, em sua tessitura, a épica, a autobiografia espiritual e o ensaio filosófico. Ele é, em muitas formas, a mais importante obra do Romantismo inglês. Embora tenha aparecido ao público em meados do século XIX e sua influência tenha sido legada às gerações posteriores ao alto Romantismo, o poema de Wordsworth figura como a culminação e a síntese de diversas vertentes e pensamentos fundamentais à poesia de sua época (i.e. subjetivismo, historicismo, idealização da natureza e da imaginação, etc.), estabelecendo-se como o genuíno épico romântico: o grande poema do 'Eu'.

Em The prelude, como o título completo informa, Wordsworth percorre o texto de sua memória, buscando nele encontrar a narrativa da formação de seu espírito, sua mente. Como escreve no prefácio à publicação de outra obra, The Excursion (à qual The Prelude serviria como introdução): "The preparatory poem is biographical, and conducts the history of the author's mind to the point when he was emboldened to hope that his faculties were sufficiently matured for entering upon the arduous labour which he had proposed to himself" (WORDSWORTH, 1995, p. 750). Ao lermos sua obra, podemos notar que ela é constituída de rememorações e meditações, de recordações de eventos passados, nos quais Wordsworth identifica o epicentro das reverberações psíquicas que deram forma ao seu espírito, e da reavaliação dessas experiências a lume da totalidade presente da experiência de Wordsworth como sujeito, ato que busca encontrar no passado a linha mestra

\footnotetext{
1 O Prelúdio ou o Desenvolvimento do Espírito de Um Poeta. Poema Autobiográfico. (Todas as traduções em notas são nossas).

2 "O poema preparatório é biográfico, e conduz a história da mente do autor até o ponto em que ele foi encorajado a ansiar que suas faculdades estivessem suficientemente amadurecidas para adentrar o árduo labor que ele havi proposto para si próprio".
}

que dá à fragmentariedade de experiências de uma vida o aspecto de totalidade característico da narrativa.

Esse é um ato não apenas de identificação, mas também de composição. Wordsworth, como escreve no poema, vê sua tarefa de autobiógrafo como um vasculhar no fundo do lago da mente, um separar os elementos que lá se encontram de fato, que compõe aquele ecossistema de forma organizada, dos reflexos transitórios, frutos da fantasia. Assim, Wordsworth perscruta sua alma em busca daqueles elementos que a compõe, que formam a base de sua imagem de si. "Dust as we are," diz o poeta,

[...] the immortal spirit grows

Like harmony in music; there is a dark Inscrutable workmanship that reconciles Discordant elements, makes them cling together

In one society. How strange, that all

The terrors, pains, and early miseries,

Regrets, vexations, lassitudes interfused

Within my mind, should e'er have borne a part,

And that a needful part, in making up

The calm existence that is mine when I

Am worthy of myself ${ }^{3}$ (Ibid., I, vv. 341-351).

É buscando compreender esse mecanismo que reconcilia na alma os elementos da experiência, que os faz formar a narrativa de sua biografia, iluminando as partes à luz do todo, que Wordsworth empenha-se na tarefa de rememoração e autoanálise.

Seguindo a categorização do filósofo alemão Walter Benjamin, podemos identificar três tipos de eventos que marcam a memória de Wordsworth: experiências, vivências e choques. As experiências compõem a maior parte das recordações: encontramse na infância de Wordsworth no campo, em meio à sua pequena comunidade rural, nas aventuras com seus amigos, nos livros que estimulam sua imaginação e nos sonhos e devaneios através dos quais contata o que há de sublime na natureza. Quanto às vivências, o poeta pouco se demora sobre elas, sempre consciente (e não sem remorso) da pobreza de

\footnotetext{
3 "Pó que somos, o espírito imortal cresce / Como a harmonia na música; existe um obscuro / $\mathrm{E}$ incompreensível trabalho que reconcilia / Os elementos discordantes e os faz unirem-se / Em uma só sociedade. Quão estranho / Que os terrores, dores e sofrimentos prematuros, / Mágoas, aborrecimentos, fadigas, todos juntos / No meu espírito, tenham alguma vez tomado parte, / E uma parte indispensável, na construção da minha calma existência que é minha quando eu / Sou digno de mim!"
} 
experiência que ofereceram a ele; mas, ainda assim, as vivências encontram lugar no relato como fundo contra o qual a luz das experiências vivas mostra-se mais nítida, especialmente nas passagens referentes à estadia do poeta em Londres. Por fim, possuem destaque especial os choques (o que a crítica denomina 'spots of time ${ }^{4}$ '), momentos marcados na memória por sua singularidade e inefabilidade, os quais assombram o biógrafo ainda anos mais tarde, sem jamais desvelarem por completo seu significado. A essas memórias Wordsworth concede maior visibilidade, sobre elas demora-se mais em seu relato, pois elas retêm para sempre algo de misterioso, de vazio, que não se deixa integrar de todo na narrativa. São esses momentos de choque que dão a estrutura para a obra: são os marcos na trajetória da rememoração, os pontos nodais que o poeta deve conectar, através do ato rememorativo do conjunto da sua vida passada e consciência presente, para poder compreender seus papeis na formação de seu espírito e integrá-los como experiência.

Tendo em vista essas considerações, buscaremos demonstrar como The prelude pode ser compreendido como um esforço de redenção: de transformação da vivência em experiência através do choque; de trasmutação do choque em experiência por um ato de conexão e integração da memória; e de compreensão da vivência como ilusão criada, por um lado, pela modernidade industrial, e, por outro, pela complacência do sujeito experienciador.

\section{Experiência, Vivência e Choque}

Segundo Walter Bejamin, em seu ensaio 'Sobre alguns temas de Baudelaire', a experiência é definida como "matéria da tradição, tanto na vida privada quanto na coletiva. Forma-se menos com dados isolados e rigorosamente fixados na memória, do que com dados acumulados, e com frequência inconscientes, que afluem à memória" (BENJAMIN, 1994, p. 105). A experiência possui um caráter formativo, marcante; age subterraneamente, moldando o indivíduo sem desenraizá-lo. Tem seus alicerces na tradição e na continuidade, especialmente na vida comunitária rural, onde o tempo flui com mais vagar e os valores são compartilhados; onde há continuidade temporal dos costumes e da visão do mundo e continuidade espacial das relações humanas, de vizinhança. Assim, "onde há experiência no sentido estrito do termo, entram em conjunção, na memória, certos conteúdos do passado individual com outros do passado coletivo" (p. 107). A experiência é, portanto, marcada por um caráter integrativo: é um evento que se encontra em relação com outros, formando uma rede ininterrupta em que os eventos particulares iluminam-se uns aos outros com significação. Nem o sujeito permanece isolado em sua experiência, pois ela sempre remete a outra tradição, outra continuidade de experiências (nunca, de fato, aparta-se dela).

Estreitamente ligado ao conceito de experiência está, para Benjamin, a ideia de narrativa: esta

não tem a pretensão de transmitir um acontecimento pura e simplesmente (como a informação o faz); integra-o à vida do narrador, para passá-lo aos ouvintes como experiência. Nela ficam impressas as marcas do narrador como os vestígios das mãos do oleiro no vaso de argila (Ibid., p. 107).

A narrativa assemelha-se à experiência em seu caráter integrativo, de organização de uma totalidade cujas partes permanecem ao mesmo tempo significativas em suas particularidades e relacionadas tanto ao conjunto quanto ao restante das partes. Ela é também, como a experiência, cumulativa, pois forma uma tradição que se transforma e se avoluma a cada iteração e recepção. Nesse sentido podemos conceber The prelude não somente como uma narrativa resultante de um acúmulo de experiências, mas também como obra que se propõe a retraçar o percurso da experiência no que podemos chamar de a 'tradição' individual da memória.

Oposta à narrativa (e representando, para o filósofo, sua atrofia), Benjamin coloca a 'informação', especialmente como ela se apresenta nos jornais, cujo objetivo "consiste em isolar os acontecimentos do

\footnotetext{
4 "Momentos" ou "marcas/manchas no tempo".
} 
âmbito onde pudessem afetar a experiência do leitor" (lbid., p. 106). Esse isolamento, ademais, segundo o filósofo, "se explica ainda pelo fato de que [a informação] não se integra à 'tradição'” (Ibid., p. 107), isto é, a informação jornalística é incapaz de criar, ou dar-se como, uma totalidade, como formulando uma experiência autêntica e significativa, passível de ser transmitida e integrada por um novo sujeito como sabedoria operacional.

Mantendo a mesma relação que a narrativa tem para com a experiência, a informação tem seu contraponto humano na vivência. A vivência, da mesma forma, caracteriza-se por sua não integração na consciência (e inconsciente) do sujeito, na sua refração para longe dele. É a experiência que se fragmentou e que aparece desintegrada. Enquanto a experiência dá-se como narrativa, organizada temporalmente e oferecendo suas partes como relacionadas e constitutivas de um todo, a vivência é pura informação, uma parte deslocada de um todo ao qual o sujeito não possui acesso, e que, portanto, não tem, para ele, valia. A vivência provém de um amortecimento da capacidade do sujeito de assimilar novas experiências, fato decorrente de uma superexposição a impressões externas que se configuram como choques: impressões exteriores que, por seu caráter de novidade, ameaçam abalar a estabilidade psíquica do sujeito.

Benjamin escreve acerca do choque:

Quanto maior é a participação do fator do choque em cada uma das impressões, tanto mais constante deve ser a presença do consciente no interesse em proteger contra os estímulos; quanto maior for o êxito com que ele operar, tanto menos essas impressões serão incorporadas à experiência, e tanto mais corresponderão ao conceito de vivência ( $p$. 111).

e

O fato de o choque ser assim amortecido e aparado pelo consciente emprestaria ao evento que o provoca o caráter de experiência vivida em sentido restrito. $E$, incorporando imediatamente este evento ao acervo das lembranças conscientes, o tornaria estéril para a experiência poética (p. 110).

Percebemos, portanto, que o choque se coloca como uma categoria entre as duas anteriores: é uma experiência nova, não integrada à narrativa do sujeito, mas ainda nova, sem ter se transformado em vivência devido a sua repetição e ao amortecimento da capacidade receptiva do sujeito. O choque é o evento singular que deve ser convertido em experiência ou vivência, ato esse dependente das faculdades e disposições do indivíduo. A reconversão da vivência em choque é o ato sobre o qual Baudelaire (para usar o caso estudado por Benjamin) fundou sua poesia; também desse recurso lançou mão Wordsworth: o poeta inglês, porém, mais operou no sentido de integrar o choque à sua experiência, ou, antes, no sentido de encontrar na sua experiência as reverberações dos choques de sua vida. Tendo essa visão em consideração, exploraremos a seguir como experiência, vivência e choque dialogam em The prelude.

\section{A Experiência Comunitária e a Experiência Individual}

A narrativa de Wordsworth inicia-se quando seu protagonista, o próprio poeta, deixa a "vast city" (WORDSWORTH, 1995, I, v. 7) pelas regiões campestres e propõe-se, tendo o espírito renovado pelo contato com a natureza, a compor uma obra épica em versos. Sem decidir-se qual tema abordar, o poeta é tomado por recordações da infância, encontrando nelas os germes de sua sensibilidade poética presente e como aqueles foram nutridos por seu amor à natureza. Seu desejo, então, volta-se para o trabalho de rememoração, para que com esse ato ele possa "be taught to understand myself" (Ibid., I, vv. 629-630), e seu interlocutor (seu amigo S. T. Coleridge, a quem o relato é dirigido), "to know / With better knowledge how the heart was framed / Of him thou lovest"' (Ibid., I, vv. 630-632). Com tal intuito de autoconhecimento, é na

\footnotetext{
7 "A saber, / Com um melhor entendimento, como o coração foi formado / Daquele que tu amas".
}

\footnotetext{
5 "Vasta cidade".

6 "Ser ensinado a me compreender".
} 
própria Natureza que Wordsworth encontra sua primeira fonte de experiência; é a Natureza que "from my first dawn / Of childhood didst [...] intertwine for me / The passions that build up our human soup" (Ibid., I, vv. 406-408). Mesmo naquele primeiro contato com a poesia e a narrativa, a canção ouvida no colo da ama, a natureza se fazia presente na forma do rio correndo ao lado de sua casa, o qual "loved / To blend his murmurs with my nurse's song ${ }^{9 "}$ (Ibid., I, vv. 271-272).

Para Wordsworth, portanto, a Natureza é a primeira e maior instrutora da alma. Nela a alma encontra um manancial inexaurível de experiências, uma tradição imorredoura e uma comunidade sempre presente. A chuva que cai forma, para o poeta, "notes that are / The ghostly language of the ancient earth" (Ibid., II, vv. 311-312), e a terra e a natureza "spake to

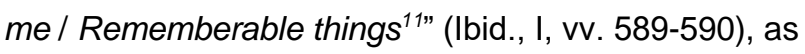
quais, por vezes, mesmo parecendo "lifeless then, and doomed to sleep ${ }^{12 "}$ (Ibid., I, vv.596), viriam a fazer parte formativa da alma do poeta, operando inconscientemente, até que "maturer seasons called them forth / To impregnate and to elevate the mind ${ }^{13}$ " (Ibid., II, vv. 597-598) (tal como descreve Benjamin o funcionamento da experiência). Em sua relação com a natureza, Wordsworth concebe-a como um todo vivo do qual faz parte:

To every natural form, rock, fruits, or flower, Even the loose stones that cover the highway, I gave a moral life: I saw them feel, Or linked them to some feeling: the great mass Lay bedded in a quickening soul, and all That I beheld respired with inward meaning ${ }^{14}$ (Ibid., III, vv. 128-133).

A Natureza, assim, aparece como o arquétipo da 'comunidade' e de todos os valores que a constituem, age como ama da criança, instrutora dos sentidos, que educa as faculdades receptivas do espírito a captar experiências em todos os lugares e

\footnotetext{
8 "Desde minha primeira aurora / De infância [...] entreteceu para mim / As paixões que vem compor a alma humana".

9 "Amava / Mesclar seus murmúrios com a canção da minha ama".

10 "Notas que são / A linguagem fantasmagórica da terra antiga".

11 "Diziam-me / Coisas memoráveis".

12 "Sem vida então, e fadadas a dormir".

13 "Estações mais maduras as convocassem / Para impregnar e elevar a mente".
}

ensina-o a integrá-las em si, da mesma forma que a natureza integra em si todas as suas variadas e infindas lições.

Em seu contato com a natureza, vemos florescer em Wordsworth o senso de comunidade, o qual, já desgastado na modernidade de um poeta como Baudelaire (sete anos separam a publicação de As flores do mal da de The Prelude), é ainda fulcral para a experiência do autor inglês. Tal senso se encontra na comunhão da amizade, no grupo de amigos de infância com os quais o poeta passa a brincar e explorar as vizinhanças de sua terra natal; está na comunhão com a Natureza, à qual o poeta sente pertencer, e com a qual convive como se cada árvore, cada pedra, rio e tudo o mais que enxerga no mundo fosse um indivíduo pronto para narrar-lhe a tradição da Natureza. E a comunidade está também, talvez especialmente para Wordsworth como poeta, no elo da tradição literária, no encontro com os grandes artífices da imaginação, aos quais não dispensa poucas palavras de louvor. Wordsworth fala de poetas e contadores de histórias como "Powers / For ever to be hallowed ${ }^{15 "}$ (Ibid., V, vv. 218-219), de canções como elos entre gerações, servindo de "Food for the hungry ears of little ones, / And of old men who have survived their joys ${ }^{16 "}$ (Ibid., V, vv. 211-212), e o poder da poesia como uma corrente cujos elos se estendem desde a épica de Homero na Grécia antiga até a canção da fiandeira na Inglaterra novecentista.

Todos esses tipos de comunhão, de troca de experiências, fundam-se, como Wordsworth tantas vezes afirma em sua obra, na própria criação do poeta, longe dos centros urbanos, em meio a uma comunidade rural, na qual cada indivíduo é familiar ao outro. Wordsworth descreve o vilarejo de sua infância como "A narrow Vale where each was known to all" onde se encontra

\footnotetext{
14 "A cada forma natural, rocha, frutos ou flores, / Mesmo as pedras soltas que cobre a estrada, / Eu dei uma vida moral: vias sentir, / Ou liguei-as a algum sentimento: a grande massa / Repousava em uma alma avivada, e tudo / O que eu contemplava respirava com significado interno".

15 "Poderes / A serem para sempre louvados".

16 "Alimento para os ouvidos famintos dos pequenos / E dos velhos que viveram para além de suas alegrias".

17 "Um vale estreito, onde cada um era conhecido por todos".
} 
some sheltering bower or sunny nook Where an old man had used to sit alone, Now vacant; pale-faced babes whom I had left In arms, now rosy prattlers at the feet Of a pleased grandame tottering up and down; And growing girls whose beauty, filched away With all its pleasant promises, was gone To deck some slighted playmate's homely cheek $^{18}$ (Ibid., II, vv. 198-208).

Em meio a esse comunidade, "The face of every neighbour whom I met / Was like a volume to

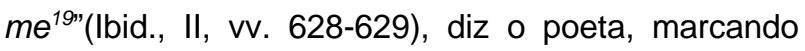
como a vida rural, diferentemente da vida metropolitana (como Wordsworth notará em Londres), é propícia ao desenvolvimento das capacidades receptivas do sujeito: este não é bombardeado por uma miríade de impressões que deve recusar em prol de sua saúde psíquica, mas, antes, vai em busca de impressões, das quais extrai as experiências que o constituem.

\section{A Metrópole e a Vivência do Choque}

Aos olhos de Wordsworth, contrário à tranquilidade da vida campestre, assoma-se o caótico turbilhão da vida londrina. De fato, quando recorda sua primeira impressão de Londres, Wordsworth usa a palavra "choque": "Three years had flown / Since I had felt in heart and soul the shock / Of the huge town's first presence, and had paced / Her endless streets, a transient visitant ${ }^{20 "}$ (Ibid., VII, vv. 65-68).. Assim caracteriza a cidade: um lugar de choque, de ruas sem fim, onde o poeta pode permanecer apenas como visitante transitório, incapaz de firmar raízes. A descrição que Wordsworth faz da cidade, embora marcadamente romântica, não está longe daquela que

\footnotetext{
18 "Algum lugar recoberto ou recanto ensolarado, / Onde um velho costumava se sentar sozinho, agora vago; bebês de face pálida, o quais deixei / Ainda em braços, agora tagarelas rosados aos pés / Da avó contente, correndo de um lado ao outro; / E garotas amadurecendo, cuja beleza, roubada / Junto com todas as suas aprazíveis promessas, foi / Adornar a face de alguma amiga desprezada".

19 "O rosto de cada vizinho que eu encontrava / Era como um livro para mim".

20 "Três anos se passaram / Desde que eu senti no coração e na alma o choque / Da primeira presença da cidade imensa, e caminhei / Suas ruas sem fim, um visitante transitório".

21 "torrente infinita de homens e coisas moventes".
}

Poe e Baudelaire fazem da urbe. É o local onde o senso de comunidade se desintegra, onde a vizinhança e a comunhão, tão importantes para Wordsworth e sua visão do mundo, fragmenta-se em existências isoladas e anônimas. Londres apresenta uma "endless stream of men and moving things ${ }^{21}$ " (lbid., VII, vv. 151), uma "quick dance / Of colours, lights, and forms; the deafening din; / The comers and the goers face to face, / Face after face; the string of dazzling wares, / Shop after shop ${ }^{22 "}$ (Ibid., VII, vv. 154158). Outra característica da cidade marcada por Wordsworth é a desindividualização a que sujeita os indivíduos. Onde antes esses eram marcados e denomidados por suas funções ("the woodman", "the shepherd ${ }^{23 ",}$ em minúsculas), agora tornam-se tipos (em maiúsculas), repetições desindividualizadas encontradas em todos os centros urbanos: "the Nurse is here, / The Bachelor, that loves to sun himself, / The military Idler, and the Dame24" (Ibid., VII, vv. 207-210),.

A única descrição que Wordsworth é capaz de formar da cidade não é mais do que uma coleção de impressões concatenadas metonimicamente. De tal modo a cidade recusa-se a compor uma totalidade, uma imagem completa, que o autor recorre, para descrevê-la, a conduzir o leitor imaginativamente pelas ruas da cidade: "we turn / Abruptly into some sequestered nook ${ }^{25 "}$ (Ibid., VII, vv. 169-170); "through tracts of thin resort, / And sights and sounds that come at intervals, / We take our way. A raree-show is here, ${ }^{26 "}$ (Ibid., VII, vv. 172-174); "Thence back into the throng, until we reach, / Following the tide that slackens by degrees, / Some half-frequented scene, where wider streets / Bring straggling breezes of suburban air. / Here files of ballads dangle from dead walls,27"' (Ibid.,

\footnotetext{
22 "dança rápida / De cores, luzes e formas; o ruído ensurdecedor; / Os que vem e os que vão, face a face, / Face após face; a sucessão de deslumbrantes produtos, / Loja após loja".

23 "o lenhador", "o pastor".

24 "A Ama está aqui, / O Solteirão, que ama o sol, / O Ocioso militar, e a Dama".

25 "viramos / Abruptamente em um canto retirado".

26 "Por caminhos de pouca afluência, / E cenas e sons que vem a intervalos, / Prosseguimos. Um espetáculo ambulante há aqui". 27 "Dali, de volta à multidão, até atingirmos, / Seguindo a corrente que principia a decrescer / Algum lugar pouco frequentado, onde ruas mais largas / Trazem brisas dispersas de ar suburbano. / Aqui um estendal com baladas pende das paredes nuas".
} 
VII, vv. 189-193). E a descrição prossegue ininterruptamente, sem fim em vista, até que o autor vê-se forçado a interromper bruscamente a descrição: "Enough,28" (Ibid., VII, vv. 219). Percebemos, então, a partir dessas considerações, que, de fato, as impressões que a cidade oferece a tal ponto encontram-se fragmentadas que são incapazes de compor uma totalidade acabada que constitua uma memória singular remissível, o que é característico da experiência; antes, a cidade é apenas presentificável, dada como compondo-se no instante em que é observada.

A cidade, assim, é quase que puramente vivência, e nela o poeta permanece em um estado liminar: passa pela cidade e sua torrente de impressões desconexas, mas jamais sente-se em casa, não é capaz de abarcar a totalidade de impressões como um conjunto que exprima uma experiência harmônica, é incapaz de integrar a cidade como experiência senão negativamente, como fundo contra o qual tenta resgatar de seu âmago um lampejo de experiência humana singular, como veremos a seguir.

\section{A Redenção da Vivência pelo Choque}

A ameaça da metrópole, da grande massa anônima, ainda que ocupando um pequeno espaço nas divagações de Wordsworth (comparado a outros temas), e abordada, o leitor sente, não sem certa relutância por parte do poeta, é ainda sentida na obra de Wordsworth como uma sombra que ameaça engolfar e apagar o brilho e a pureza do "indivíduo natural”. Como Baudelaire, Wordsworth caminha na contracorrente da multidão. Ambos se horrorizam da modernidade e da vertiginosa urbe, mas, enquanto aquele a toda hora sente-se ser seduzido por ela,

\footnotetext{
28 "Basta;"

29 "A face de cada um / Que passa por mim é um mistério!"

30 "Um relâmpado... depois a noite!"

31 "Como a tempestade negra sobre o cume da montanha / Contrasta com o raio de sol no vale, assim / Aquela imensa massa humana a fermentar / Serve como um grave fundo ou contraste, / Para formas e objetos singulares, de onde retiram, / Por sentimento e olhar contemplativo, / Mais do que vivacidade e poder próprios".
}

Wordsworth, ainda romântico, esforça-se por resgatar da massa, em um ato de compaixão e empatia, um lampejo de humanidade singular: "The face of every one / That passes by me is a mystery!" ${ }^{29 "}$ (Ibid., VII, vv. 628-629), afirma o poeta em um ato de recusa à vivência. Baudelaire encontra em sua passante o choque de uma súbita paixão anônima e fugaz; Wordsworth, por sua vez, encontra, na súbita visão de um pedinte cego, o contato com a humanidade que se esconde na massa.

Wordswoth compara a multidão a uma negra tempestade que deixa escapar um raio de luz (Baudelaire fala em "Un éclair... puis la nuit?o"):

As the black storm upon the mountain top Sets off the sunbeam in the valley, so That huge fermenting mass of human-kind Serves as a solemn back-ground, or relief, To single forms and objects, whence they draw, For feeling and contemplative regard,

More than inherent liveliness and power ${ }^{31}$ (lbid., VII, vv. 619-625).

Esse raio de luz é o choque do encontro com a figura de um pedinte:
[...] lost
Amid the moving pageant, I was smitten Abruptly, with the view (a sight not rare) Of a blind Beggar, who, with upright face, Stood, propped against a wall, upon his chest Wearing a written paper, to explain
His story, whence he came, and who he was ${ }^{32}$ (Ibid., VII, vv. 634-642).

Mas esse choque não permanece apenas como tal, abre-se em oportunidade de genuína experiência:

\begin{abstract}
Caught by the spectacle my mind turned round As with the might of waters; and apt type This label seemed of the utmost we can know, Both of ourselves and of the universe; And, on the shape of that unmoving man, His steadfast face and sightless eyes, I gazed, As if admonished from another world ${ }^{33}$ (lbid., VII, vv. 643-649).
\end{abstract}

\footnotetext{
32 “... perdido / No meio do cortejo que passava, fui assaltado / Abruptamente pela visão (uma cena não rara) / De um Pedinte cego, que, de rosto erguido, / De pé, escorado contra uma parede, em seu peito / Levando um papel escrito que explicava / Sua história, de onde viera e quem era".

33 "Tomada pelo espetáculo, minha mente revolveu-se / Como se pelo poder das águas; e um tipo apto / Esse letreiro parecia de tudo o que podemos saber, / Ambos acerca de nós mesmos e do universo; / E, sobre a forma daquele homem imóvel, / Sua face impassível e olhos apagados, eu fixei o olhar, / Como se admoestado de um outro mundo".
} 
Como em Baudelaire, a torrente de choques inassimiláves abre espaço por instante para singularizar um evento, a vivência recua como fundo para dar forma a um evento e torná-lo passível de assimilação. No caso de Baudelaire, poeta da modernidade, o evento não é assimilado como experiência: permanece choque, sem reverberações no espírito do poeta, salvo como choque desrealizado, apenas forma sem conteúdo. Em Wordsworth, por outro lado, é o conteúdo humano que se destaca, e, pelo ato de singularização desse conteúdo, é ele redimido e tornado experiência, integrado em uma narrativa (a da biografia do poeta): a torrente da vivência é interrompida por um instante, é desacelerada por ato volitivo de atenção, através do qual a cidade pode ser percebida como constituida de eventos singulares, não de uma massa de impressões amorfas.

A redenção da vivência pelo choque, de fato, é um motivo corrente em The Prelude. Em uma lembrança de sua juventude, a figura de um andarilho, veterano de guerra, aparece como um choque que desperta o poeta da dissipação de sua juventude. Wordsworth recorda-se de certa época de sua juventude, quando os prazeres da sociedade e suas distrações faziam-no esquecer de seu desejo por exepriências autências, "When from our better selves we have too long / Been parted by the hurrying world, and droop, / Sick of its business, of its pleasures tired ${ }^{34 "}$ (Ibid., IV, vv. 355-377). Assim meditando, recorda a vez em que, deixando uma festa tarde da noite e retornando para casa sob a luz do luar, depara-se com um andarilho na estrada. Em um primeiro momento assusta-se com a aparência fantasmagórica da figura, mas logo, censurando-se, convida-o para seguir com ele. O poeta nota: "Companionless, / No dog attending, by no staff sustained, / He stood, and in his very dress appeared / A desolation, a simplicity, / To which the trappings of a gaudy world / Make a strange back-

34 "Quando de nossa melhor parte estamos já há muito / Apartados pelo mundo apressado, e nos abatemos / Cansados de sua lida, de seus prazeres enfastiados".

35 "Sem companheiro, / Nenhum cão o acompanhando, sem o apoio de um cajado, / Ele permanecia, e em suas próprias vestes ground ${ }^{35 " \prime}$ (Ibid., IV, vv. 401-406). Aqui opera o mesmo ato de singularização que mais tarde se repetirá no encontro com o pedinte londrino: o "gaudy world" da multiplicidade de impressões (lá, a metrópole, aqui, a dissipação juvenil) recuam ante a imagem de um homem simples e solitário, e esta visão, operando como choque, urge o poeta a voltar ao seus ideais de solidão artística, a voltar do mundo da vivência (onde confessa perder-se) ao da experiência.

\section{A Redenção do Choque pela Experiência}

Como vimos, o choque, para Wordsworth, no contexto da vivência metropolitana, opera no sentido de resgatar a capacidade para a experiência. $\mathrm{Na}$ arquitetura narrativa de The Prelude, porém, o choque possui outra característica. Segundo o crítico Jonathan Bishop, "at the center of our experience of The Prelude are those 'spots of time' where Wordsworth is endeavoring to express key moments in the history of his imagination" 36 " (BISHOP, 1959, p. 45). Esses 'spots of time', aos quais nos referimos aqui como eventos de choque, são aqueles momentos em que o poeta vê-se diante de uma experiência que transcende sua compreensão, e que, portanto, permanecem parcialmente inassimilados pela consciência. Tais lembranças encontram-se espalhados pela obra como marcos na trajetória de vida de Wordsworth. São momentos como a visão da montanha na forma de um gigante, a qual despertou em Wordsworth, quando criança, a consciência da Natureza como uma entidade de inteligência própria; também é a visão do corpo do garoto afogado no rio Winander, a primeira visita aos Alpes, entre outras memórias. Todos esses momentos têm em comum a gravidade com que marcaram o espírito do jovem poeta e o fato de carregarem um excesso de significado que evade a compreensão no instante da apreensão. Segundo Bishop, "What we seem to have are fragments of a drama, moments in a single action which has retired

\footnotetext{
aparentava / Uma desolação, uma simplicidade, / Contra as quais as armadilhas de um mundo extravagante / Forma um estranho fundo".

36 "no centro de nossa experiência de O Prelúdio estão aqueles 'lugares no tempo', onde Wordsworth esforça-se para expressar momentos-chave na história de sua imaginação".
} 
behind the reach of direct expression, leaving in our hands fragments of imagery ${ }^{37 "}$ (Ibid., p. 51). Ainda assim, embora não compreendida, a experiência desses choques "remain[s] / Where still it works, though hidden from all search / Among the depths of time ${ }^{38 "}$ (WORDSWORTH, 1995, V, vv. 195-197).

Não obstante, esse conjunto de fragmentos (pois não surgem à consciência em sua integridade), ao serem postos em contato, no exercício de rememoração, com a totalidade da experiência de vida do poeta, são feitos a se relacionarem com outros objetos da memória e, assim, pela iluminação mútua entre partes e todo, fragmentos e narrativa contínua, revelam o significado seu que permaneceu oculto à primeira impressão consciente. Por esse ato é o poeta "taught / To understand myself' (Ibid., I, vv. 629-630); ele, porém, em sua crônica, não explicita as ligações entre os momentos de choque e sua experiência geral: registra-as antes no movimento do pensamento associativo (o estilo que dá forma à obra), como quando a memória de fantasias infantis, de "huge and mighty forms, that do not live / Like living men, ${ }^{39 "}$ que "moved slowly through the mind / By day, and were a trouble to my dreams ${ }^{40 "}$ (Ibid., I, vv. 399-401), suscita na estrofe seguinte um hino à Natureza e ao seu poder de dar forma à alma humana através das experiências que oferece:

\begin{abstract}
Wisdom and Spirit of the universe! Thou Soul that art the eternity of thought That givest to forms and images a breath And everlasting motion, not in vain By day or star-light thus from my first dawn Of childhood didst thou intertwine for me The passions that build up our human soult1 (Ibid., I, vv. 402-408).
\end{abstract}

Assim, enquanto o choque, pelo contraste com as experiências e pela meditação sobre o próprio, é integrado por fim à imagem de totalidade que o autor forma de si, ainda assim as ligações não são

\footnotetext{
37 "O que parece que temos são fragmentos de um drama, momentos em uma ação singular que se retirou para atrás do alcance da expressão direta, deixando em nossas mãos fragmentos de imagens".

38 "permanece / Onde ainda opera, embora oculta a toda procura / Entre as profundezas do tempo".

39 "imensas e possantes formas, que não vivem / Como homens vivem"
}

explicitadas a ponto de tornarem-se fixas: são aproximadas 0 suficiente para tornarem-se compreensíveis, mas permanecem ainda parcialmente veladas e, portanto, vivas.

\section{Conclusão}

Em nossa leitura de alguns excertos de The prelude, buscamos compreender 0 ato de rememoração autobiográfica, seu propósito e o que atinge, à luz das categorias de experiência, vivência e choque do filósofo Walter Benjamin. Notamos que as três espécies de experiência fazem-se presente como memória, e todas relacionam-se de forma a se iluminarem, cada qual agindo ora como fundo, ora como forma. A experiência, ao lado da vivência, dá a medida da pobreza da segunda; a vivência, por sua vez, forma o fundo contra o qual a forma da experiência, como choque, transparece; por último, o choque, posto em contexto pela soma das experiências, transforma-se ele próprio em experiência. Concluímos, desse modo, que uma análise de The prelude baseada nos conceitos benjaminianos põe em evidência a estrutura psicológica da obra, tanto como monumento artístico quanto como documento da dialética rememorativa operada pelo seu autor.

\footnotetext{
40 "moviam-se vagarosamente pela mente / De dia, e eram uma perturbação aos meus sonhos".

41 "Sabedoria e Espírito do universo! / Tu, Alma, que és a eternidade do pensamento, / Que dás às formas e às imagens um alento / E sempiterno movimento, não em vão, / À luz do dia ou de estrelas, assim, desde minha primeira aurora / De infância tu entreteceste para mim / As paixões que formam a alma humana".
} 


\section{Referências}

BENJAMIN, W. Sobre alguns temas em Baudelaire. In: . Obras Escolhidas. Vol. 3. São Paulo: Brasiliense, 1994. pp. 103-149.

BISHOP, J. Wordsworth and the "Spots of Time". ELH, vov. 26 , no. 1,1959 . pp. 45-65.

WORDSWORTH, W. The Prelude. In: The

Collected Poems of William Wordsworth. Ware, Hertfordshire: Wordsworth Editions, 1995. pp. 750892.

\section{COMO CITAR ESSE ARTIGO}

DE AGUIAR, Angiuli Copetti. A experiência comunitária e a vivência da metrópole: o prelúdio, de William Wordsworth, à luz de Walter Benjamin. Signo, Santa Cruz do Sul, v. 45, n. 82, jan. 2020. ISSN $1982-2014$. Disponível em: <https://online.unisc.br/seer/index.php/signo/article/view/14162>.

Acesso em: doi:https://doi.org/10.17058/signo.v45i82.14162. 